\title{
Refining a Church-Based Lifestyle Intervention Targeting African-American Adults at Risk for Cardiometabolic Diseases: A Pilot Study
}

\author{
Yuan E. Zhou1*, Cynthia D. Jackson1, Veronica J. Oates², Gerald W. Davis ${ }^{3}$, Carolyn Davis", \\ Kushal A. Patel ${ }^{7}$, Maciej S. Buchowski ${ }^{8}$, David G. Schlundt ${ }^{9}$, Margaret K. Hargreaves ${ }^{1}$ \\ ${ }^{1}$ Department of Internal Medicine, Meharry Medical College, Nashville, TN, USA \\ ${ }^{2}$ Department of Family and Consumer Sciences, Tennessee State University, Nashville, TN, USA \\ ${ }^{3}$ Ralph H Boston Wellness Center, Tennessee State University, Nashville, TN, USA \\ ${ }^{4}$ Walden University, Minneapolis, MN, USA \\ ${ }^{5}$ Participant and Clinical Interactions Resources, Meharry Medical College, Nashville, TN, USA \\ ${ }^{6}$ Department of Epidemiology and Biostatistics, University of South Carolina, Columbia, USA \\ ${ }^{7}$ Department of Public Health, Tennessee State University, Nashville, USA \\ ${ }^{8}$ School of Medicine, Vanderbilt University, Nashville, TN, USA \\ ${ }^{9}$ Department of Psychology, Vanderbilt University, Nashville, TN, USA \\ Email: *yzhou@mmc.edu
} Zudi-Mwak Takizala ${ }^{1}$, Richmond A. Akatue ${ }^{1}$, Konya Williamss, Jianguo Liu ${ }^{1}$, James R. Hébert ${ }^{6}$,

How to cite this paper: Zhou, Y.E., Jackson, C.D., Oates, V.J., Davis, G.W., Davis, C., Takizala, Z.-M., Akatue, R.A., Williams, K., Liu, J.G., Hébert, J.R., Patel, K.A., Buchowski, M.S., Schlundt, D.G. and Hargreaves, M.K. (2017) Refining a ChurchBased Lifestyle Intervention Targeting African-American Adults at Risk for Cardiometabolic Diseases: A Pilot Study. Open Journal of Epidemiology, 7, 96-114. https://doi.org/10.4236/ojepi.2017.72009

Received: January 5, 2017

Accepted: April 18, 2017

Published: April 21, 2017

Copyright $\odot 2017$ by authors and Scientific Research Publishing Inc. This work is licensed under the Creative Commons Attribution International License (CC BY 4.0).

http://creativecommons.org/licenses/by/4.0/

\begin{abstract}
Objective: The pilot study was intended to test the feasibility of a multiple-component lifestyle intervention targeting African American adults in a weight control and cardiometabolic risk reduction program on diet, activity, and stress, using community-engagement principles. Methods: Applying mixed qualitative and quantitative measures, the intervention had a two-part sequential study design consisting of 12 weekly small group sessions that provided individual and group counseling in nutrition, exercise, and mindfulness, while incorporating focus group and interactive techniques to learn about barriers and acceptable practices for this population. The program was implemented at an African-American church in Nashville, Tennessee. Results: Thirty-four participants (aged $56.1 \pm 11$ years, body mass index (BMI) $36.7 \pm$ $6.6 \mathrm{~kg} / \mathrm{m}^{2}$ ) completed the intervention. Lifestyle changes after the 12 weekly sessions showed some positive trends including reduced sodium intake (from $2725.3 \pm 326.5$ to $2132 \pm 330, \mathrm{mg} /$ day, $\mathrm{P}=0.008$ ), increased walking steps (from $4392.1 \pm 497.2$ to $4895.3 \pm 497.9$, steps/day, not significant), and slightly decreased Perceived Stress Scale (PSS) scores (from $13.7 \pm 1.4$ to $12.4 \pm 1.5$, not significant). Body fat $\%$ among male participants decreased significantly (from $33.8 \pm 2.6$ to $28 \pm 2.6, \%, \mathrm{P}=0.043$ ). Among cardiometabolic risk biomarkers, hemoglobin Alc (HbAlc) decreased significantly (from $6.6 \pm 0.2$ to
\end{abstract}


$6.1 \pm 0.2, \%, \mathrm{P}<0.001)$. The baseline PSS score was positively associated with baseline adiposity levels (e.g., weight, $\beta=2.4, \mathrm{P}=0.006$ ). Twenty-one participants took part in focus groups during the program to identify barriers to healthy lifestyle changes. Primary barriers reported were price, time for preparing healthy meals, unfamiliarity with mindfulness activities, their health condition, and daily schedule available for physical activities. Conclusions: This church-based pilot intervention was proven feasible by showing modest progress in reducing adiposity and decreasing HbA1c levels. The focus group and interactive methods facilitated program direction. Future full-scale studies are warranted to identify key strategies that provide more personalized approaches and supportive environments to sustain a healthy lifestyle among these at risk minorities with limited resources.

\section{Keywords}

Pilot Study, Life Style Risk Reduction, Mind-Body Therapies, Cardiometabolic Disease, Weight Control, Church-Based Health Program, African Americans

\section{Introduction}

Lifestyle-related diseases disproportionately afflict African American populations. From 2009-2012, obesity affected 38\% and 58\% of African American males and females aged 20 years and over respectively, compared to $35 \%$ and $36 \%$ respectively among males and females of the general population in the same age group [1]. Age-adjusted leisure time inactivity was prevalent among 19\% and $25 \%$ of African American males and females compared to $10 \%$ and $12 \%$ respectively for Caucasians males and females [2]. Obesity has been associated with a substantial increase in risk of type 2 diabetes [3] [4] [5], and cardiovascular disease and mortality [6] [7] [8] [9]. Physical inactivity was an independent risk factor for type 2 diabetes [10] [11] [12] and for cardio-metabolic markers related to risk of cardiovascular diseases [13] [14]. The age-adjusted prevalence of hypertension and diabetes was $42 \%$ and $15 \%$ respectively among African American adults, compared to $31 \%$ and $10 \%$ among the total population from 1999-2006 [15].

Health promotion interventions among African Americans in faith-based organizations have been documented [16] [17]. Conventional dietary weight loss programs have focused typically on caloric intake restriction and increases in physical activities [16]. The majority of the church-based programs showed improved risk factor outcomes [17]. Effect size has varied, for example, ranging from 1.1 to $6.1 \mathrm{~kg}$ among males [18] [19]. Emerging evidence suggests that mindfulness practice can help to curb obesity-related behaviors and therefore would be beneficial for weight management [20]. Mindfulness is intended to pay attention to one's internal and external experience on a moment to moment basis [21]. It applies skills such as the body scan, breathing, and yoga postures, which can be integrated into daily activities, including standing and eating [21]. 
Mindfulness based stress reduction practice has been positively related to reduced stress, depression and anxiety [22] since psychological maladjustments have been associated with eating disorders and obesity [23]. Yet, there has been no published community based obesity intervention applying these three components simultaneously among African Americans.

We conducted a pilot program to evaluate the feasibility of future large fullscale intervention programs. The design of this lifestyle intervention was described previously (The Biomedical/Obesity Reduction Trial) [24] and was implemented in the St. James Missionary Baptist Church, Nashville, with the church's collaboration. The primary objective was to examine to what extent a church-based intervention simultaneously targeting nutrition, physical activity and mindfulness practice might help in weight management and might ameliorate cardio-metabolic risks among middle-aged and older African Americans. The second objective was to examine whether baseline stress levels would be predictive of weight control after the intervention. The third objective was to assess participants' perceptions of the healthy living lifestyle program. Primary outcomes were changes in weight, the diabetic risk indicator Hemoglobin A1c (HbAlc), and serum lipids. Secondary outcomes were changes in the association of the baseline stress measure with pre- and post-intervention adiposity levels. Tertiary outcomes were participants' feedback on their barriers when adapting to healthy living practices during the program. In summary, the study provided key information on the mix of variables important in fashioning the behavioral approaches in this population.

\section{Methods}

\subsection{Overview of Study Design}

The intervention consisted of 12 weekly education sessions promoting healthy eating, being physically active, and meditation to reduce stress. It targeted (1) encouraging the daily consumption of wholesome food and a pescetarian diet (i.e. vegetarian diets that include seafood); (2) daily moderate-intensity physical activity; and (3) meditation practice on six days per week [24]. The $1^{\text {st }}$ round was implemented in Feburary to May of 2013 and the $2^{\text {nd }}$ round was conducted in March to early June of 2015.

A focus group was implemented among the $1^{\text {st }}$ round participants prior to the $2^{\text {nd }}$ round, in order to obtain their feedback on barriers and suggested improvements during the program. For the transcribed audio data and notes from the focus groups, codes were generated based on key words, and emerging themes were identified.

Prior to the intervention, researchers contacted the Church pastor and discussed with him study goals and protocol, and received his commitment to participate actively. The intervention was conducted in group sessions to provide a strong supporting social milieu for participants. The time of group sessions was fitted into the church's schedule of activities. Data were collected at the baseline and after the 12 weekly interventions. The study was approved by the Institu- 
tional Review Board (IRB) at Meharry Medical College and a written informed consent was signed by all participants before the study.

Based on principles of social cognitive theory and the theory of planned behavior, the intervention aimed at helping participants to adapt to healthier living through participation in focus groups and weekly interactive sessions, by improving their behavioral skills, identifying barriers and challenges to improve their self-efficacy, and providing supportive social norms for them.

\subsection{Recruitment}

The pastor made the announcement to the congregation at church, and participants were recruited as a convenience sample from among those interested. The eligibility for this study included being 21 years of age or older, self-defined as African American, English speaking, having a body mass index (BMI) above 25 $\mathrm{kg} / \mathrm{m}^{2}$, having telephone access, and being willing and able to provide informed consent and participate in the weekly intervention sessions. Exclusion criteria were less than 21 years old, a continuing malignant cancer diagnosis, and/or any condition that would preclude participation in the exercise component, unintentional weight loss in excess of five pounds in the previous 3 months, pregnancy or lactation, inflammation-related conditions such as rheumatoid arthritis, Crohn's disease, ulcerative colitis, and any psychiatric illness (these last conditions requiring a doctor's approval). Three individuals dropped out during the intervention due to surgery, conflict with work time, and household responsibilities. In total, 34 individuals completed the program.

\subsection{Intervention Content and Delivery}

The 12 weekly intervention sessions were on a weekday's afternoon, with half an hour each for the three behaviors-nutrition, physical activity, and mindfulness stress reduction practice, led by a registered dietitian, a physical activity trainer, and a psychologist respectively. Participants were weighed prior to each session. During each session, educational handouts for these three sections were distributed as well as recipes. Topics covered during the sessions included: (1) nutrition: reading food labels, protein and carbohydrates and fats, whole grain and beans, spices, herbs, and salt, meal planning, and grocery shopping; (2) physical activities: cardiorespiratory exercises, weights, abdominal exercises, and stretching exercises; (3) mindfulness practice: understanding emotions, how to begin, mindfulness skills (breathing, stretching, yoga), and expanding mindfulness (mindful eating, mindful walking).

Based on feedback from focus groups and the interactive exchanges during the sessions, the dietitian, physical activity trainer and psychologist provided advice to participants during individual and group counseling at each of their sessions. For example, the dietitian might discuss meal planning with participants, the trainer might demonstrate moderate floor exercises, and the psychologist might talk about various ways of practicing mindfulness, among other possible topics that the participants introduced. 
The pastor also delivered a presentation "You and Your Body" with biblical scriptures aligned with healthy lifestyle messages. Dinner based on selected healthy eating recipes was provided at completion of the sessions on exercise and meditation. During dinner, participants discussed healthy eating with the study dietitian, and discussed ways to overcome barriers and challenges that surfaced during the focus groups and the interactive exchanges at each behavioral session.

\subsection{Data Collection}

\subsubsection{Focus Groups}

The focus group conversation was recorded, and emerging themes on the barriers to and facilitators of healthy eating, being active, and practicing mindfulness were summarized by coding the scripts.

\subsubsection{Psychological, Dietary, Physical Activity, Anthropometric Data}

At the baseline visit, participants completed self-administered questionnaires including the demographic information and Perceived Stress Scale (PSS) [25]. Participants were also instructed to complete 24-h dietary records and to wear a BodyMedia Fit Armband (BodyMedia, Pittsburgh, USA) for at least four days (two weekend days and two weekdays). Height was measured in feet and inches using a portable SECA 213 stadiometer (SECA, Chino, USA) and recorded to the nearest 0.1 inch. Weight and body fat\% were assessed using a portable body composition analyzer Tanita scale (Tanita Corporation, Tokyo, Japan). Weight was recorded to the nearest $0.1 \mathrm{lbs}$.

At the completion of the 12 weekly sessions, dietary intake, physical activity levels and anthropometric measures were collected again.

\subsubsection{Clinical Data}

At the baseline visit, systolic and diastolic blood pressures were measured using a digital OMRON HEM-907XL blood pressure monitor (OMRON, Kyoto, Japan), and recorded to the nearest $0.1 \mathrm{mmHg}$. Blood was drawn from each participant and collected in EDTA vacutainers and one plain tube. An aliquot of whole blood was stored at $4^{\circ} \mathrm{C}$ for analysis of $\mathrm{HbAlc}$. Serum specimens were stored at $4^{\circ} \mathrm{C}$ for blood lipids (total cholesterol, LDL-cholesterol, HDL-cholesterol). Blood samples were then sent to QUEST Diagnostics (QUEST Diagnostics, Madison, USA) for analysis.

At the completion of the 12 weekly sessions, blood samples were taken again for the $\mathrm{HbAlc}$ and lipid measures.

Participants were given a $\$ 25$ gift card at each data-gathering clinic.

\subsection{Data Analyses}

The 24-h dietary records in the $1^{\text {st }}$ round were analyzed using the University of Minnesota's Nutrition Coordinating Center nutrient database, and 24-h dietary records in the $2^{\text {nd }}$ round was analyzed by the Food Processor 10.15.20 (ESHA Research, Salem, USA). Each participant's dietary intake was examined by the same software, and macronutrient intake was expressed as a percentage of the 
energy consumption. Sense Wear Professional 8.1 software (Body Media, Pittsburgh, USA) was used to assess physical activity from movement data collected through armbands. Primary outcomes were pre- and post-changes in blood lipids, HbA1c, body weight/BMI, and \% body fat.

\subsection{Statistical Analyses}

Mixed linear models (SAS PROC MIXED) were conducted to examine pre- and post-intervention outcomes. Independent variables included baseline levels of possible confounders such as age, gender, education, and employment. Linear Regressions were computed with dependent variables being adiposity levels at baseline or adiposity changes between the pre- and post-intervention, and PSS as the independent variable and age as the covariate. Statistical analyses were conducted using Statistical Analysis System software, SAS 9.3 (SAS Institute, Inc., Cary, NC). A statistical significance level was determined at $\mathrm{P}<0.05$.

\section{Results}

\subsection{Participants' Perceptions of the Intervention}

Twenty-one individuals from the 12 weekly intervention sessions participated in the focus groups (16 females and 5 males, $\geq 41$ years, all with high school education) (Table 1). Key findings from the focus groups showed that main barriers to adopting healthier diets were taste preference, unfamiliar recipes or cooking methods, time to prepare foods, and cost. Challenges for being active included health conditions, such as knee problems, and lack of time or feeling tired after dealing with other daily obligations (Table 1). On the other hand, improved behavioral skills as a result of the program were reported, including better dietary intake, becoming used to exercise, putting mindfulness into daily practice by slowing down, and a strengthened bond with fellow program participants (Table $1)$.

\subsection{Intervention Outcomes}

\subsubsection{Baseline}

Thirty-four individuals ( 25 females and 9 males) participated in the intervention (aged $56.1 \pm 11$ years, BMI $36.7 \pm 6.6$, systolic blood pressure $137.2 \pm 21.7$ $\mathrm{mmHg}$, diastolic blood pressure $83.4 \pm 10 \mathrm{mmHg}$ ) (Table 2). Only one participant was a current smoker.

\subsubsection{Changes in Dietary Intake, Physical Activity, and Perceived Stress Scores (PSS)}

Among changes in self-reported dietary intake, were decreased energy consumption $(1668.1 \pm 176.6$ to $1275.5 \pm 179.4$, kcal/day; $\mathrm{P}=0.027)$, increased $\%$ energy from protein $(17.7 \pm 1.3$ to $21.9 \pm 1.3, \%$; $\mathrm{P}<0.001)$, decreased $\%$ energy from fat $(40.3 \pm 1.6$ to $37.3 \pm 1.6, \% ; \mathrm{P}=0.079)$, and decreased sodium intake $(2725.3 \pm 326.5$ to $2132 \pm 330, \mathrm{mg} /$ day; $\mathrm{P}=0.008)$ (Table 3$)$. Daily walking steps increased from $4392.1 \pm 497.2$ to $4895.3 \pm 497.9$ (not significant) (Table 3 ). After 12 weeks, questionnaire derived PSS scores slightly decreased (from $13.7 \pm$ 
1.4 to $12.4 \pm 1.5$, not significant).

\subsubsection{Changes in Adiposity and Biochemical Measures}

After 12 weeks' intervention, body fat $\%$ was reduced among males $(33.8 \pm 2.6$ to

Table 1. Focus group themes and subthemes ${ }^{1}$.

\begin{tabular}{|c|c|}
\hline Themes & Subthemes \\
\hline \multicolumn{2}{|l|}{ Motivation } \\
\hline Weight & $\begin{array}{l}\text { - Desire or need to lose weight } \\
\text { - } \quad \text { Nice appearance with less weight }\end{array}$ \\
\hline Health & $\begin{array}{l}\text { - Personal health issues, such as being diabetic or pre-diabetic } \\
\text { - Family history, such as diabetes } \\
\text { - Benefits of previous weight loss attempts, such as improved } \\
\text { diabetic risk indicator HbAlc levels, self and others' weight loss }\end{array}$ \\
\hline Information & - Becoming informed about healthy living and disease prevention \\
\hline \multicolumn{2}{|c|}{ Changes since participating in the program } \\
\hline Starting to exercise & $\begin{array}{l}\text { - Going to gym } \\
\text { - } \quad \text { Exercising from not at all to it becoming easier }\end{array}$ \\
\hline Eating in the right way & $\begin{array}{l}\text { - } \text { Reduced consumption of meat } \\
\text { - } \text { Eating vegetables } \\
\text { - } \text { Not eating fried foods or other fast food } \\
\text { - } \quad \text { Drinking less soda and drinking more water } \\
\text { - } \text { Cooking according to recipes received from the program } \\
\text { - } \text { Replacing regular milk with reduced fat milk or skim milk } \\
\text { - } \text { Portion control } \\
\text { - } \quad \text { Eating slowly }\end{array}$ \\
\hline Weight change & $\begin{array}{l}\text { - Loss of weight } \\
\text { - Lost weight but gained it back }\end{array}$ \\
\hline Others & - Formed closer relationship with peers \\
\hline \multicolumn{2}{|l|}{ Barriers } \\
\hline Healthy eating & $\begin{array}{l}\text { - } \text { Cost of foods } \\
\text { - } \text { Food preparation, time and method } \\
\text { - Taste preference }\end{array}$ \\
\hline Physical activities & $\begin{array}{l}\text { - Tiredness } \\
\text { - Not able to keep doing exercise at home/after the program } \\
\text { - } \quad \text { Being physically demanding } \\
\text { - Poor health }\end{array}$ \\
\hline Mindfulness practices & - Difficult to do \\
\hline
\end{tabular}

$\mathrm{l}=21$, including 16 females and 5 males, $\geq 41$ years, all with high school education. 
Table 2. Baseline characteristics of the participants.

\begin{tabular}{|c|c|}
\hline Participants' characteristics ${ }^{1}$ & All \\
\hline Age (year) & $56.1 \pm 11$ \\
\hline Female (\%) & 73.5 \\
\hline \multicolumn{2}{|l|}{ Employment $(\%)^{2}$} \\
\hline No & 12.5 \\
\hline Retired & 37.5 \\
\hline Yes & 50 \\
\hline \multicolumn{2}{|l|}{ Education $(\%)^{3}$} \\
\hline Less than high school & 3.3 \\
\hline High school & 26.7 \\
\hline Some college (including associate degree) & 36.7 \\
\hline College and above & 33.3 \\
\hline BMI (Body Mass Index, $\mathrm{kg} / \mathrm{m}^{2}$ ) & $36.7 \pm 6.6$ \\
\hline Systolic blood pressure (mmHg) & $137.2 \pm 21.7$ \\
\hline Diastolic blood pressure (mmHg) & $83.4 \pm 10$ \\
\hline Obesity (BMI $\geq 30)(\%)$ & 91.2 \\
\hline \multicolumn{2}{|l|}{ Drinking (\%) } \\
\hline Never & 28.1 \\
\hline Previously & 21.9 \\
\hline Current & 50 \\
\hline \multicolumn{2}{|l|}{ Current smoker (\%) } \\
\hline Never & 70.6 \\
\hline Previously & 26.5 \\
\hline Current & 2.9 \\
\hline Perceived Stress Scale (PSS) & $13.6 \pm 7.6$ \\
\hline \multicolumn{2}{|l|}{ Medication usage } \\
\hline Hypertension (\%) & 38.2 \\
\hline Hyperlipidemia (\%) & 29.4 \\
\hline Diabetes (\%) & 17.7 \\
\hline
\end{tabular}

${ }^{1}$ mean $\pm \operatorname{STD}(\mathrm{n}=34) ;{ }^{2} \mathrm{n}=32 ;{ }^{3} \mathrm{n}=30$.

$28 \pm 2.6, \mathrm{P}=0.043$ ) (Table 3). During the same period of time, 41.2\% participants lost at least $5 \mathrm{lbs}$ and $14.7 \%$ lost $5 \%$ or more body weight (Table 3). Among biomarkers, HbA1c was reduced significantly $(6.6 \pm 0.2$ to $6.1 \pm 0.2, \mathrm{P}<0.001)$ (Table 3). Also reduced were cholesterol levels (total, $163.7 \pm 7.2$ to $148 \pm 7.4$, $\mathrm{P}=0.034$; HDL, $49.5 \pm 2.3$ to $37.7 \pm 2.3, \mathrm{P}<0.001$; LDL, $97.9 \pm 6.5$ to $96.5 \pm 6.6$, not significant) (Table 3 ).

\subsubsection{Baseline PSS as the Predictor of Baseline Adiposity Measures and} Adiposity Level Changes between Pre- and Post-Intervention

At baseline, the stress score PSS demonstrated a positive association with adiposity levels (weight, $\beta=2.4, \mathrm{P}=0.006$; BMI, $\beta=0.4, \mathrm{P}=0.013$ ) (Table 4). After adjustment for age, these associations were weakened (weight, $\beta=1.5, \mathrm{P}=0.083$; 
Table 3. Changes in dietary intake, physical activity, adiposity, and biochemical measures at baseline and the end of the 12 weekly sessions.

\begin{tabular}{|c|c|c|c|}
\hline Measures & Baseline $^{1}$ & End of the 12 weekly sessions ${ }^{1}$ & $\mathrm{P}$ \\
\hline \multicolumn{4}{|l|}{ Dietary intake ${ }^{2}$} \\
\hline Energy (Kcal/day) & $1668.1 \pm 176.6$ & $1275.5 \pm 179.4$ & 0.027 \\
\hline Protein (\%) & $17.7 \pm 1.3$ & $21.9 \pm 1.3$ & $<0.001$ \\
\hline Fat $(\%)$ & $40.3 \pm 1.6$ & $37.3 \pm 1.6$ & 0.079 \\
\hline Carbohydrate (\%) & $42.5 \pm 2.3$ & $41.1 \pm 2.4$ & 0.443 \\
\hline Sodium (mg/day) & $2725.3 \pm 326.5$ & $2132 \pm 330$ & 0.008 \\
\hline \multicolumn{4}{|l|}{ Physical activity } \\
\hline Total energy expenditure $(\mathrm{kcal})^{3}$ & $2502.9 \pm 112.4$ & $2484.1 \pm 112.6$ & 0.712 \\
\hline Sedentary activity time (h/day) ${ }^{4}$ & $14.3 \pm 0.4$ & $14.4 \pm 0.4$ & 0.99 \\
\hline Moderate activity time $(\mathrm{min} / \text { day })^{5}$ & $117.3 \pm 16.1$ & $124.9 \pm 16.1$ & 0.347 \\
\hline Steps(step/day) ${ }^{3}$ & $4392.1 \pm 497.2$ & $4895.3 \pm 497.9$ & 0.209 \\
\hline \multicolumn{4}{|l|}{ Stress score } \\
\hline Perceived stress scale ${ }^{5}$ & $13.7 \pm 1.4$ & $12.4 \pm 1.5$ & 0.12 \\
\hline \multicolumn{4}{|l|}{ Adiposity $^{6}$} \\
\hline Weight $(\mathrm{lb})^{7}$ & $208.5 \pm 6.4$ & $206.8 \pm 6.5$ & 0.171 \\
\hline BMI & $35.6 \pm 1.1$ & $35.2 \pm 1.1$ & 0.149 \\
\hline Body fat $\%(\text { male })^{8}$ & $33.8 \pm 2.6$ & $28 \pm 2.6$ & 0.043 \\
\hline Body fat $\%$ (female $)^{9}$ & $44.7 \pm 1.4$ & $43.9 \pm 1.5$ & 0.552 \\
\hline \multicolumn{4}{|l|}{ Biochemical measures $^{10}$} \\
\hline Total cholesterol (mg/dL) & $163.7 \pm 7.2$ & $148 \pm 7.4$ & 0.034 \\
\hline LDL-cholesterol (mg/dL) & $97.9 \pm 6.5$ & $96.5 \pm 6.6$ & 0.782 \\
\hline HDL-cholesterol (mg/dL) & $49.5 \pm 2.3$ & $37.7 \pm 2.3$ & $<0.001$ \\
\hline HbA1C (\%) & $6.6 \pm 0.2$ & $6.1 \pm 0.2$ & $<0.001$ \\
\hline
\end{tabular}

${ }^{1}$ Adjusted for age, participation order, mean \pm standard err; ${ }^{2} n=26$ for all $;{ }^{3} n=31 ;{ }^{4} n=30 ;{ }^{5} n=24 ;{ }^{6} n=33$; ${ }^{7}$ Atthe completion of 12 weekly sessions, $41.2 \%$ participants lost $\geq 5 \mathrm{lbs}$ and $14.7 \%$ participants lost $\geq 5 \%$ body weight. ${ }^{8} n=9 ;{ }^{9} n=24 ;{ }^{10} n=34$ for all except for HbAlc (\%) ( $\left.n=33\right)$.

Table 4. Regression models predicting adiposity at baseline and change between pre- and post-intervention by stress score at baseline.

\begin{tabular}{cccccccc}
\hline & \multicolumn{3}{c}{ Model 1 $^{1}$} & \multicolumn{3}{c}{ Model $2^{2}$} \\
\hline Weight (baseline) & $\beta$ & SE & P & $\beta$ & SE & $\mathrm{P}$ \\
\hline Body fat\% (baseline) & 2.4 & 0.8 & 0.006 & 1.5 & 0.9 & 0.083 \\
BMI (baseline) & 0.3 & 0.2 & 0.171 & 0.2 & 0.2 & 0.398 \\
Weight change & 0.4 & 0.1 & 0.013 & 0.3 & 0.2 & 0.07 \\
Body fat\% change & -0.0 & 0.2 & 0.711 & 0.0 & 0.2 & 0.729 \\
BMI change & -0.0 & 0.2 & 0.85 & 0.0 & 0.2 & 0.646 \\
\hline
\end{tabular}

${ }^{1}$ Model 1: PSS score as the independent variable ( $\left.\mathrm{n}=34\right) ;{ }^{2}$ Model 2: PSS score as the independent variable, age as the co-variable $(\mathrm{n}=34)$. 
BMI, $\beta=0.3, \mathrm{P}=0.07$ ) (Table 4). In the current study, the baseline PSS did not show significant associations with subsequent adiposity changes during the intervention.

\section{Discussion}

\subsection{Impact of the Intervention on Weight Control and Cardiometabolic Risk Factors at 12 Weeks}

The current church-based weight control pilot intervention with multiple components among a group of middle-aged and older African Americans showed modest improvement, with one third and $15 \%$ of the participants having achieved at least $5 \mathrm{lbs}$ and $5 \%$ of body weight reduction respectively after 12 weekly intervention sessions. Other favorable changes included a reduction of HbA1c by roughly $0.5 \%(\mathrm{P}<0.001)$.

\subsection{Impact of Cardiorespiratory Workouts on Weight Control}

Participants in the current study were physically inactive since their average steps per day at baseline were less than 5000 steps per day [26] [27] [28]. Considering the health condition of participants as well as their feedback in focus group and interactions during the sessions, the program applied light to moderate levels of cardiorespiratory workouts during these sessions to cater to participants' different needs, including brisk walking, crunches or reverse crunches, leg kicks or lift, arm lift with weights, squatting and stretching.

The improvements in daily walking steps, although not significant, suggested it was possible to have motivated participants to engage in light exercise such as walking. The program lasted from early spring to late spring, and the seasonality may have contributed to more outdoor activities which would have driven up walking steps and moderate activity time. In this case, an increase of total energy expenditure would be expected.

However, in contrast, the current study observed a lack of change in total energy expenditure among our participants, which was reported previously to occur among elderly participants undergoing a physical activity intervention [29]. It was possible that our participants consciously engaged in more walking during the program, but became more "inactive" during the rest time. On the other hand, even light or moderate activities can still contribute to health benefits. A meta-analysis study showed walking for even one hour per week gave protection against coronary heart disease, stroke and overall cardiovascular disease [30]. For current study participants who were at risk of chronic diseases or had to cope with competing demands of family and work obligations, benefits of light or moderate activities or less sedentary time are an encouraging message that can help motivate them to be more active.

\subsection{Impact of Mindfulness Practices on Stress Control}

In line with the available evidence regarding effects of mindfulness practices on stress control [31], slightly reduced PSS scores were observed in the current 
study. Compared to clinical settings, much fewer interventions were documented that applied mindfulness practice in community settings. Reduced PSS scores were reported after an 8 weeks' course on mindfulness [32] [33]. In other studies, though no significant changes in the severity of stress were observed, other benefits were reported, such as improved mood and sleep [34] and ameliorated metabolic syndrome risks [35].

\subsection{Associations of Stress Levels with Baseline Adiposity and Changes in Adiposity}

The baseline stress score was positively related to baseline adiposity, which is consistent with the literature. The link between stress and obesity and abdominal obesity has been well documented [36]. Such associations were driven by both physiological factors (e.g., stress hormone cortisol) and psychosocial factors (e.g., stress related eating behaviors) [36] [37]. In the current study, no significant correlations were observed between baseline PSS and the weight loss effect, but the small sample size may have weakened the power to detect a significant association should it have been present. In a US weight loss trial, the perceived stress was predictive of weight regain during the maintenance period in previous weight loss interventions [38] [39]. Future interventions with larger sample size are warranted to provide more evidence on how baseline stress levels might predict weight loss levels, and take into consideration emotional management in obesity prevention.

In the current study, the experience of one participant may exemplify the potential benefits of mindfulness practice on weight management. She reported gaining 6.4 pounds during 12 weekly sessions, but a loss of 11.2 pounds during the 3 months' period after the completion of sessions when she had more attentively practiced mindfulness stress reduction to curb emotional eating.

\subsection{The Nature of the Specific Dietary Changes}

The nutrition education curriculum was developed with a focus on caloric control for weight loss, and meal planning for healthy eating. In response to main health issues among our targeted populations (e.g., 38.2\%, 29.4\% and $17.7 \%$ participants reported on taking medications for hypertension, hyperlipidemia and diabetes respectively at the baseline visit) and overcoming main barriers to adopt healthier diets, the focus groups were conducted to understand participants' perspectives on the program. Barriers included preparation time, cost, and taste preferences, against which we targeted small but tangible and affordable changes (Table 1). For example, one focus of the curriculum was to reduce sodium intake by replacing salt with herbs and spices in recipes, given (1) the average blood pressure measured at the baseline survey, which was around the prehypertension benchmark (120 - $139 \mathrm{mmHg}$ and $80-89 \mathrm{mmHg}$ for systolic blood pressure and diastolic blood pressure respectively) [40]; and (2) the traditionally high dietary sodium consumption in the southeastern USA [41]. This recommendation appeared to be readily adopted as the self-reported sodium intake 
was reduced among the majority of participants in the program.

Improved glycemic control indicated by the reduced blood HbAlc was observed in the current study, suggesting that messages delivered by the program, e.g., portion control and the increase of consumption of plant protein as opposed to animal protein, was effective. A systematic review and meta-analyses reported an average of $0.41 \% \mathrm{Hb} \mathrm{A} 1 \mathrm{c}$ reduction by Mediterranean diets [42], which is similar to the pescetarian diet recommended in the current program. Thus, the approximately $0.5 \% \mathrm{HbA} 1 \mathrm{c}$ reduction in the current study was a substantial improvement $(\mathrm{P}<0.012)$ in glycemic control.

After 12 weeks, serum cholesterol levels, particularly total-cholesterol levels and HDL-cholesterol levels, decreased, while the LDL-cholesterol levels did not change. It is difficult to interpret these findings which appear to indicate that dietary intake behavior change had occurred among participants. Our conclusion is supported by the reduced \% energy from the fat intake along with the increased \% energy from the protein intake among participants during the program. In previous dietary studies, similar acute changes of cholesterol profiles were reported through reduced consumption of animal meat [43] [44], or through modified diets, i.e., switching from high-fat to low-fat, or replacing saturated fatty acids by polyunsaturated fatty acids [45] [46] [47] [48]. In addition to absolute cholesterol levels, an improved cholesterol profile, e.g, the reduced ratio of LDL-cholesterol to HDL-cholesterol, was observed in some studies [46] but not others. A previous metabolic study suggests that during dietary changes the reduction of HDL-cholesterol is due to the slower formation of HDL-cholesterol particles [48], thus would be temporary and less worrisome. Future interventions should work on optimizing lipid profiles during the intervention, i.e., reducing LDL-cholesterol levels while improving the LDL-cholesterol to HDL-cholesterol ratio.

During the intervention, recipes with a short list of ingredients were more likely to be tried by participants at home. "Eggplant pizzettes" was such an example. With just five ingredients and less than half an hour needed for preparation, this dish was listed as one of the most liked recipes and some participants mentioned that they had tried this recipe at home during the survey after the 12 weekly intervention. On recipe handouts, we listed the estimated price of each dish with the majority of them being less than $\$ 5$ per serving. We tried to introduce a variety of ethnic dishes, but "stir fried tofu" or "lentil loaf" was rather poorly received. Substituting fish for red meat in the meal was well accepted, with items such as "tuna casserole" and "salmon macaroni salad". Traditionally, southern black diets, or so called "soul food", mainly consisted of pork/bacon, lard, sugar, molasses, chicken and cornmeal [49]. Other than sweet potatoes, vegetables were "peripheral foods" which included cabbage, collard greens, and mustard greens, and were usually cooked by being boiled with pork fat until they tasted "rich" [49]. Although urbanization and other social changes over time have introduced variety into African Americans' diets, the cultural influence still exists in their food choices today [50], as the high-fat and salt and low-fiber diets 
were independent of socio-economic status among African Americans [51]. In the current study, 24-h dietary records at the completion of 12 weekly sessions showed that participants still mostly consumed foods they had been accustomed to prior to the program. They did report on having tried healthier ways of food preparation, e.g., using baking instead of frying. Our experience suggests that ease of preparation, convenience and familiarity are a major key to adopting healthy dietary habits.

\subsection{Impact of the Partnership on Project Activities}

The current study exemplifies a collaboration between academic researchers and community partners who have built an enduring community engaged research relationship. African American churches provide established social networks in which maladaptive lifestyles can be addressed [52]. The pastor and his wife were actively involved in the program and served as peer models. The pastor delivered healthy living messages which were integrated with bible scripture. The pastor's wife and other church members assisted with food preparation. Involvement of the pastor and his wife in these ways is probably a unique feature of this program. Also, the church has facilities for group activities which serves as a supportive environment for exercise [53] [54] [55]. Some of the participants commented that coming to the group exercise at the church was how they could motivate themselves to reach their goal of doing workouts twice a week at home. Preliminary results of our outcomes were disseminated among the participants promptly through email or regular mail.

\section{Limitations and Strengths of the Study}

Limitations of the present study include a relatively small sample and a pre-post design with no control group. However, such pilot studies are necessary to better understand the methods and procedures applied and to improve future programs on a larger scale [56] [57]. The small sample size may have contributed to some of the non-significant effects of the intervention, but study results will help in calculating the sample size for a future intervention. Food intake was self-reported, which could not rule out effects of social desirability attitudes of participants with respect to underreporting and/or over-reporting [58]. Two nutrient analysis softwares were used for nutrient analysis in round 1 and 2 respectively due to the availability of the two nutrition data systems at the time of data analysis, but dietary intake of each participant was analyzed by the same software to examine the pre- and post-intervention difference(s). Blood pressure and PSS data were collected only at baseline.

The majority of participants were women. Women usually play the role of gatekeeper for the family, particularly in meal preparation. Educating women could be helpful to let intervention messages reach the entire family, but negative comments from the family about healthy diets can also discourage women from putting more effort into cooking healthy meals, based on comments from our participants. Thus, creating a supportive family environment should be con- 
sidered in the future. Furthermore, future interventions should emphasize the recruitment of male participants, for whom limited publications have been available [18]. Some previous studies applied a supporting buddy component, i.e., letting participants invite their spouse or friends to attend the program together [59] [60], which could help to recruit more male participants.

The age of participants ranged from 45 to 77 years. Thus participants were different from each other regarding their health conditions and employment status (e.g., fully employed, unemployed, retired) and family obligations (e.g., living with young children, living alone, etc). Consequently, they dealt with different barriers or facilitators, such as expense, time, and/or daily priorities for planning meals, engaging in physical activities, and coping with stress. In this program, the participants had a chance to communicate with the counselors either through group discussion or one-on-one exchanges during the sessions, but such exchanges were limited by the time available. A small proportion of participants reported on taking medicine to control their blood lipid levels $(29.4 \%)$ and blood glucose levels (17.7\%) at baseline. We did drop the data of one participant who reported on starting to take medications for the diabetic condition after the program was initiated.

Major strengths of the current study included the collection of blood samples to measure cardiometabolic biomarkers, and Armband data to obtain an objective measure of physical activity levels.

\section{Conclusions : Lessons Learned and Future Directions}

Based on our experience with this pilot program, we suggest that (1) modifying meals with foods that participants are familiar with, instead of introducing novel foods may be more feasible for dietary change on the long term; (2) performing exercises that can be integrated into daily housework activities or can be carried out indoors may better help to reduce sedentary activity time, such as prolonged TV watching and sitting. Also, for sustainability, regular group exercise sessions at convenient locations such as church or other convenient locations should be encouraged after the intervention is completed; (3) engaging in activities such as yoga, deep breathing, and/or listening to soft music at home is a feasible approach for the participants to practice mindfulness, and practicing on a regular basis should be emphasized; and (4) providing more accessible personalized health messages may enhance the efficacy and sustainability of interventions. Getting feedback through focus groups and interactive exchanges throughout the intervention sessions was a key feature for successful program development and implementation in the current program.

Future interventions are warranted to personalize intervention approaches on coping with emotional eating, encouraging age- and physically-appropriate physical activities, applying feasible and affordable dietary modifications among at risk minorities with limited resources. Also, future church-based interventions with larger sample size and control are warranted to examine how baseline characteristics such as stress levels may be predictive of program outcomes. Further, 
as a more accurate and objective assessment approach, biomarkers should be used to monitor behavioral changes. Findings from this pilot study would be helpful in the development of future community based interventions on weight control, and amelioration of diabetes and cardiovascular disease risk factors.

\section{Acknowledgements}

This research was supported by NIDDK grant 1 P30 DK092986 from the National Institute of Diabetes and Digestive and Kidney Diseases, and CNPC grant 3 U54 CA1 S3708-03 and GMAP grant 3U54CA153708-02S2 and 3U54CA15370803S2 from the National Cancer Institute. We are thankful for the St. James Missionary Baptist Church Pastor Brooks and all St. James Missionary Baptist Church FAN participants for their collaboration throughout the program.

\section{References}

[1] Center for Disease Control and Prevention (2014) Health of Black or African American Non-Hispanic Population. http://www.cdc.gov/nchs/fastats/black-health.htm

[2] Marshall, S.J., Jones, D.A., Ainsworth, B.E., Reis, J.P., Levy, S.S. and Macera, C.A. (2007) Race/Ethnicity, Social Class and Leisure-Time Physical Inactivity. Medicine and Science in Sports and Exercise, 39, 44-51. https://doi.org/10.1249/01.mss.0000239401.16381.37

[3] Colditz, G.A., Willett, W.C., Stampfer, M.J., Manson, J.E., Hennekens, C.H., Arky, R.A. and Speizer, F.E. (1990) Weight as a Risk Factor for Clinical Diabetes in Women. American Journal of Epidemiology, 132, 501-513.

https://doi.org/10.1093/oxfordjournals.aje.a115686

[4] Chan, J.M., Rimm, E.B., Colditz, G.A., Stampfer, M.J. and Willett, W.C. (1994) Obesity, Fat Distribution and Weight Gain as Risk Factors for Clinical Diabetes in Men. Diabetes Care, 17, 961-969. https://doi.org/10.2337/diacare.17.9.961

[5] Hu, F.B., Manson, J.E., Stampfer, M.J., Colditz, G., Liu, S., Solomon, C.G. and Willett, W.C. (2001) Diet, Lifestyle and the Risk of Type 2 Diabetes Mellitus in Women. The New England Journal of Medicine, 345, 790-797. https://doi.org/10.1056/NEJMoa010492

[6] Wienpahl, J., Ragland, D.R. and Sidney, S. (1990) Body Mass Index and 15-Year Mortality in a Cohort of Black Men and Women. Journal of Clinical Epidemiology, 43, 949-960.

[7] Stevens, J., Plankey, M.W., Williamson, D.F., Thun, M.J., Rust, P.F., Palesch, Y. and O'Neil, P.M. (1998) The Body Mass Index-Mortality Relationship in White and African American Women. Obesity Research, 6, 268-277. https://doi.org/10.1002/j.1550-8528.1998.tb00349.x

[8] Owen, C.G., Kapetanakis, V.V., Rudnicka, A.R., Wathern, A.K., Lennon, L., Papacosta, O., Cook, D.G., Wannamethee, S.G. and Whincup, P.H. (2015) Body Mass Index in Early and Middle Adult Life: Prospective Associations with Myocardial Infarction, Stroke and Diabetes over a 30-Year Period: The British Regional Heart Study. BMJ Open, 5, e008105.

https://doi.org/10.1136/bmjopen-2015-008105

[9] Avenell, A., Broom, J., Brown, T.J., Poobalan, A., Aucott, L., Stearns, S.C., Smith, W.C., Jung, R.T., Campbell, M.K. and Grant, A.M. (2004) Systematic Review of the Long-Term Effects and Economic Consequences of Treatments for Obesity and 
Implications for Health Improvement. Health Technology Assessment, 8, 1-182. https://doi.org/10.3310/hta8210

[10] Lynch, J., Helmrich, S.P., Lakka, T.A., Kaplan, G.A., Cohen, R.D., Salonen, R. and Salonen, J.T. (1996) Moderately Intense Physical Activities and High Levels of Cardiorespiratory Fitness Reduce the Risk of Non-Insulin-Dependent Diabetes Mellitus in Middle-Aged Men. Archives of Internal Medicine, 156, 1307-1314. https://doi.org/10.1001/archinte.1996.00440110073010

[11] Hu, F.B., Sigal, R.J., Rich-Edwards, J.W., Colditz, G.A., Solomon, C.G., Willett, W.C., Speizer, F.E. and Manson, J.E. (1999) Walking Compared with Vigorous Physical Activity and Risk of Type 2 Diabetes in Women: A Prospective Study. Journal of American Medical Association, 282, 1433-1439. https://doi.org/10.1001/jama.282.15.1433

[12] Hu, F.B., Li, T.Y., Colditz, G.A., Willett, W.C. and Manson, J.E. (2003) Television Watching and Other Sedentary Behaviors in Relation to Risk of Obesity and Type 2 Diabetes Mellitus in Women. Journal of American Medical Association, 289, 1785 1791. https://doi.org/10.1001/jama.289.14.1785

[13] Chastin, S.F., Palarea-Albaladejo, J., Dontje, M.L. and Skelton, D.A. (2015) Combined Effects of Time Spent in Physical Activity, Sedentary Behaviors and Sleep on Obesity and Cardio-Metabolic Health Markers: A Novel Compositional Data Analysis Approach. PLoS ONE, 10, e0139984. https://doi.org/10.1371/journal.pone.0139984

[14] Ekelund, U., Luan, J., Sherar, L.B., Esliger, D.W., Griew, P. and Cooper, A. (2012) Moderate to Vigorous Physical Activity and Sedentary Time and Cardiometabolic Risk Factors in Children and Adolescents. Journal of American Medical Association, 307, 704-712. https://doi.org/10.1001/jama.2012.156

[15] Fryar, C.D., Hirsch, R., Eberhardt, M.S., Yoon, S.S. and Wright, J.D. (2010) Hypertension, High Serum Total Cholesterol and Diabetes: Racial and Ethnic Prevalence Differences in U.S. Adults, 1999-2006. NCHS Data Brief, 36, 1-8.

[16] Lancaster, K.J., Carter-Edwards, L., Grilo, S., Shen, C. and Schoenthaler, A.M. (2014) Obesity Interventions in African American Faith-Based Organizations: A Systematic Review. Obesity Reviews, 15, 159-176. https://doi.org/10.1111/obr.12207

[17] DeHaven, M.J., Hunter, I.B., Wilder, L., Walton, J.W. and Berry, J. (2004) Health Programs in Faith-Based Organizations: Are They Effective? American Journal of Public Health, 94, 1030-1036. https://doi.org/10.2105/AJPH.94.6.1030

[18] Newton, R.L., Griffith, D.M., Kearney, W.B. and Bennett, G.G. (2014) A Systematic Review of Weight Loss, Physical Activity and Dietary Interventions Involving African American Men. Obesity Reviews, 15, 93-106. https://doi.org/10.1111/obr.12209

[19] Kong, A., Tussing-Humphreys, L.M., Odoms-Young, A.M., Stolley, M.R. and Fitzgibbon, M.L. (2014) Systematic Review of Behavioural Interventions with Culturally Adapted Strategies to Improve Diet and Weight Outcomes in African American Women. Obesity Reviews, 15, 62-92. https://doi.org/10.1111/obr.12203

[20] O’Reilly, G.A., Cook, L., Spruijt-Metz, D. and Black, D.S. (2014) Mindfulness-Based Interventions for Obesity-Related Eating Behaviours: A Literature Review. Obesity Reviews, 15, 453-461. https://doi.org/10.1111/obr.12156

[21] Baer, R.A. (2003) Mindfulness Training as a Clinical Intervention: A Conceptual and Empirical Review. Clinical Psychology. Science and Practice, 10, 125-143. https://doi.org/10.1093/clipsy.bpg015

[22] Abbott, R.A., Whear, R., Rodgers, L.R., Bethel, A., Thompson Coon, J., Kuyken, W., Stein, K. and Dickens, C. (2014) Effectiveness of Mindfulness-Based Stress Reduc- 
tion and Mindfulness Based Cognitive Therapy in Vascular Disease: A Systematic Review and Meta-Analysis of Randomised Controlled Trials. Journal of Psychosomatic Research, 76, 341-351.

[23] Puhl, R. and Suh, Y. (2015) Stigma and Eating and Weight Disorders. Current Psychiatry Reports, 17, 552. https://doi.org/10.1007/s11920-015-0552-6

[24] Martinez, D.J., Turner, M.M., Pratt-Chapman, M., Kashima, K., Hargreaves, M.K., Dignan, M.B. and Hébert, J.R. (2016) The Effect of Changes in Health Beliefs among African-American and Rural White Church Congregants Enrolled in an Obesity Intervention: A Qualitative Evaluation. Journal of Community Health, 41, 518-525. https://doi.org/10.1007/s10900-015-0125-y

[25] Cohen, S. and Williamson, G. (1988) Perceived Stress in a Probability Sample of the United States. In: Spacapan, S. and Oskamp, S., Eds., The Social Psychology of Health, Sage, Newbury Park.

[26] Tudor-Locke C. and Bassett D.R. Jr. (2004) How Many Steps/Day Are Enough? Preliminary Pedometer Indices for Public Health. Sports Medicine, 34, 1-8. https://doi.org/10.2165/00007256-200434010-00001

[27] Tudor-Locke, C., Craig, C.L., Thyfault, J.P. and Spence, J.C. (2013) A Step-Defined Sedentary Lifestyle Index: <5000 Steps/Day. Applied Physiology, Nutrition and $\mathrm{Me}-$ tabolism, 38, 100-114. https://doi.org/10.1139/apnm-2012-0235

[28] Sisson, S.B., Camhi, S.M., Tudor-Locke, C., Johnson, W.D. and Katzmarzyk, P.T. (2012) Characteristics of Step-Defined Physical Activity Categories in U.S. Adults. American Journal of Health Promotion, 26, 152-159. https://doi.org/10.4278/ajhp.100326-QUAN-95

[29] Thomas, G.N., Macfarlane, D.J., Guo, B., Cheung, B.M., McGhee, S.M., Chou, K.L., Deeks, J.J., Lam, T.H. and Tomlinson, B. (2012) Health Promotion in Older Chinese: A 12-Month Cluster Randomized Controlled Trial of Pedometry and "Peer Support". Medicine and Science in Sports and Exercise, 44, 1157-1166. https://doi.org/10.1249/MSS.0b013e318244314a

[30] Oguma, Y. and Shinoda-Tagawa, T. (2004) Physical Activity Decreases Cardiovascular Disease Risk in Women: Review and Meta-Analysis. American Journal of Preventive Medicine, 26, 407-418.

[31] Khoury, B., Sharma, M., Rush, S.E. and Fournier, C. (2015) Mindfulness-Based Stress Reduction for Healthy Individuals: A Meta-Analysis. Journal of Psychosomatic Research, 78, 519-528.

[32] Demarzo, M.M. Andreoni, S., Sanches, N., Perez, S., Fortes, S. and Garcia-Campayo, J. (2014) Mindfulness-Based Stress Reduction (MBSR) in Perceived Stress and Quality of Life: An Open, Uncontrolled Study in a Brazilian Healthy Sample. Explore, 10, 118-120.

[33] Geary, C. and Rosenthal, S.L. (2011) Sustained Impact of MBSR on Stress, WellBeing and Daily Spiritual Experiences for 1 Year in Academic Health Care Employees. Journal of Alternative and Complementary Medicine, 17, 939-944. https://doi.org/10.1089/acm.2010.0335

[34] Carlson, K.J., Silva, S.G., Langley, J. and Johnson, C. (2013) Mindful-Veteran: The Implementation of a Brief Stress Reduction Course. Complementary Therapies in Clinical Practice, 19, 89-96.

[35] Daubenmier, J., Moran, P.J., Kristeller, J., Acree, M., Bacchetti, P., Kemeny, M.E., Dallman, M., Lustig, R.H., Grunfeld, C., Nixon, D.F., Milush, J.M., Goldman, V., Laraia, B., Laugero, K.D., Woodhouse, L., Epel, E.S. and Hecht, F.M. (2016) Effects of a Mindfulness-Based Weight Loss Intervention in Adults with Obesity: A Randomized Clinical Trial. Obesity, 24, 794-804. https://doi.org/10.1002/oby.21396 
[36] Bjorntorp, P. (2001) Do Stress Reactions Cause Abdominal Obesity and Comorbidities? Obesity Reviews, 2, 73-86. https://doi.org/10.1046/j.1467-789x.2001.00027.x

[37] Torres, S.J. and Nowson, C.A. (2007) Relationship between Stress, Eating Behavior and Obesity. Nutrition, 23, 887-894.

[38] Brantley, P.J., Stewart, D.W., Myers, V.H., Matthews-Ewald, M.R., Ard, J.D., Coughlin, J.W., Jerome, G.J., Samuel-Hodge, C., Lien, L.F., Gullion, C.M., Hollis, J.F., Svetkey, L.P. and Stevens, V.J. (2014) Psychosocial Predictors of Weight Regain in the Weight Loss Maintenance Trial. Journal of Behavioral Medicine, 37, 11551168. https://doi.org/10.1007/s10865-014-9565-6

[39] Sarlio-Lahteenkorva, S., Rissanen, A. and Kaprio, J. (2002) A Descriptive Study of Weight Loss Maintenance: 6 and 15 Year Follow-Up of Initially Overweight Adults. International Journal of Obesity and Related Metabolic Disorders, 24, 116-125. https://doi.org/10.1038/sj.ijo.0801094

[40] Center for Disease Control and Prevention (2014) Measuring Blood Pressure. http://www.cdc.gov/bloodpressure/measure.htm

[41] Hall, W.D., Ferrario, C.M., Moore, MA, Hall, J.E., Flack, J.M., Cooper, W., Simmons, J.D., Egan, B.M., Lackland, D.T., Perry, M. and Roccella, E.J. (1997) Hypertension-Related Morbidity and Mortality in the Southeastern United States. The American Journal of the Medical Sciences, 313, 195-209. https://doi.org/10.1097/00000441-199704000-00002

[42] Ajala, O., English, P. and Pinkney, J. (2013) Systematic Review and Meta-Analysis of Different Dietary Approaches to the Management of Type 2 Diabetes. The American Journal of Clinical Nutrition, 97, 505-516. https://doi.org/10.3945/ajcn.112.042457

[43] Nordmann, A.J., Nordmann, A., Briel, M., Keller, U., Yancy, W.S., Brehm, B.J. and Bucher, H.C. (2006) Effects of Low-Carbohydrate vs. Low-Fat Diets on Weight Loss and Cardiovascular Risk Factors: A Meta-Analysis of Randomized Controlled Trials. Archives of Internal Medicine, 166, 285-293.

https://doi.org/10.1001/archinte.166.3.285

[44] Bradlee, M.L., Singer, M.R. and Moore, L.L. (2014) Lean Red Meat Consumption and Lipid Profiles in Adolescent Girls. Journal of Human Nutrition and Dietetics, 27, 292-300. https://doi.org/10.1111/jhn.12106

[45] Schaefer, E.J., Levy, R.I., Ernst, N.D., Van Sant, F.D. and Brewer, H.B. (1981) The Effects of Low Cholesterol, High Polyunsaturated Fat and Low Fat Diets on Plasma Lipid and Lipoprotein Cholesterol Levels in Normal and Hypercholesterolemic Subjects. The American Journal of Clinical Nutrition, 34, 1758-1763.

[46] Lewis, B., Hammett, F., Katan, M., Kay, R.M., Merkx, I., Nobels, A., Miller, N.E. and Swan, A.V. (1981) Towards an Improved Lipid-Lowering Diet: Additive Effects of Changes in Nutrient Intake. The Lancet, 2, 1310-1313.

[47] Zanni, E.E., Zannis, V.I., Blum, C.B., Herbert, P.N. and Breslow, J.L. (1987) Effect of Egg Cholesterol and Dietary Fats on Plasma Lipids, Lipoproteins and Apoproteins of Normal Women Consuming Natural Diets. Journal of Lipid Research, 28, 518527.

[48] Brinton, E.A., Eisenberg, S. and Breslow, J.L. (1990) A Low-Fat Diet Decreases High Density Lipoprotein (HDL) Cholesterol Levels by Decreasing HDL Apolipoprotein Transport Rates. The Journal of Clinical Investigation, 85, 144-151. https://doi.org/10.1172/JCI114405

[49] Dirks, R.T. and Duran, N. (2001) African American Dietary Patterns at the Beginning of the 20th Century. The Journal of Nutrition, 131, 1881-1889.

[50] Hargreaves, M.K., Schlundt, D.G. and Buchowski, M.S. (2002) Contextual Factors 
Influencing the Eating Behaviours of African American Women: A Focus Group Investigation. Ethnicity \& Health, 7, 133-147.

https://doi.org/10.1080/1355785022000041980

[51] Airhihenbuwa, C.O., Kumanyika, S., Agurs, T.D., Lowe, A., Saunders, D. and Morssink, C.B. (1996) Cultural Aspects of African American Eating Patterns. Ethnicity \& Health, 1, 245-260. https://doi.org/10.1080/13557858.1996.9961793

[52] Kumanyika, S.K., Whitt-Glover, M.C. and Haire-Joshu, D. (2014) What Works for Obesity Prevention and Treatment in Black Americans? Research Directions. Obesity Reviews, 15, 204-212. https://doi.org/10.1111/obr.12213

[53] Young, D.R. and Stewart, K.J. (2006) A Church-Based Physical Activity Intervention for African American Women. Family \& Community Health, 29, 103-117. https://doi.org/10.1097/00003727-200604000-00006

[54] Peterson, J.A. and Cheng, A.L. (2011) Heart and Soul Physical Activity Program for African American Women. Western Journal of Nursing Research, 33, 652-670. https://doi.org/10.1177/0193945910383706

[55] Whitt-Glover, M.C., Hogan, P.E., Lang, W. and Heil, D.P. (2008) Pilot Study of a Faith-Based Physical Activity Program among Sedentary Blacks. Preventing Chronic Disease, 5, A51.

[56] Thabane, L., Ma, J., Chu, R., Cheng, J., Ismaila, A., Rios, L.P., Robson, R., Thabane, M., Giangregorio, L. and Goldsmith, C.H. (2010) A Tutorial on Pilot Studies: The What, Why and How. BMC Medical Research Methodology, 10, 1. https://doi.org/10.1186/1471-2288-10-1

[57] Leon, A.C., Davis, L.L. and Kraemer, H.C. (2011) The Role and Interpretation of Pilot Studies in Clinical Research. Journal of Psychiatric Research, 45, 626-629.

[58] Macdiarmid, J. and Blundell, J. (1998) Assessing Dietary Intake: Who, What and Why of Under-Reporting. Nutrition Research Reviews, 11, 231-253. https://doi.org/10.1079/NRR19980017

[59] Black, D.R., Gleser, L.J. and Kooyers, K.J. (1990) A Meta-Analytic Evaluation of Couples Weight-Loss Programs. Health Psychology, 9, 330-347. https://doi.org/10.1037/0278-6133.9.3.330

[60] McLean, N., Griffin, S., Toney, K. and Hardeman, W. (2003) Family Involvement in Weight Control, Weight Maintenance and Weight-Loss Interventions: A Systematic Review of Randomised Trials. International Journal of Obesity and Related Metabolic Disorders, 27, 987-1005. https://doi.org/10.1038/sj.ijo.0802383 
Submit or recommend next manuscript to SCIRP and we will provide best service for you:

Accepting pre-submission inquiries through Email, Facebook, LinkedIn, Twitter, etc. A wide selection of journals (inclusive of 9 subjects, more than 200 journals)

Providing 24-hour high-quality service

User-friendly online submission system

Fair and swift peer-review system

Efficient typesetting and proofreading procedure

Display of the result of downloads and visits, as well as the number of cited articles Maximum dissemination of your research work

Submit your manuscript at: http://papersubmission.scirp.org/

Or contact ojepi@scirp.org 